\title{
COMPARISON OF THE CLUTCH INITIATION OF CASPIAN AND COMMON TERNS AT LAKE WINNIPEG
}

by Kees Vermeer, Canadian Wildlife Service, Edmonton

Incidental to an investigation of mercury contamination of eggs of Caspian Terns (Hydropogne caspia) and Common Terns (Sterna hirundo) during the summer of 1971 on Little George Island, $52^{\circ} 52^{\prime} \mathrm{N}, 97^{\circ} 47^{\prime} \mathrm{W}$, in Lake Winnipeg, Manitoba, data were collected on clutch initiation of the two tern species.

From June 4 to August 7, 1971 daily observations were made on Common and Caspian Terns on Little George Island, which is located 16 miles from the nearest mainland. For comparison, the clutch initiation of Common Terns was also investigated during the last week of May and the first four days of June, 1971 at Kawinaw Lake, which is at the same latitude and 70 miles west of Little George Island. Fig. 1 shows the location of Little George Island in northern Lake Winnipeg as well as the location of Kawinaw. Lake. Little George Island consists of 117 acres, is covered with trees and contains a pond. Approximately 1,000 nests of Caspian Terns and 700 nests of Common Terns were found on the island. About 150 pairs of Herring Gulls (Larus argentatus) were also nesting there. The Caspian Terns nested on a sandy area without

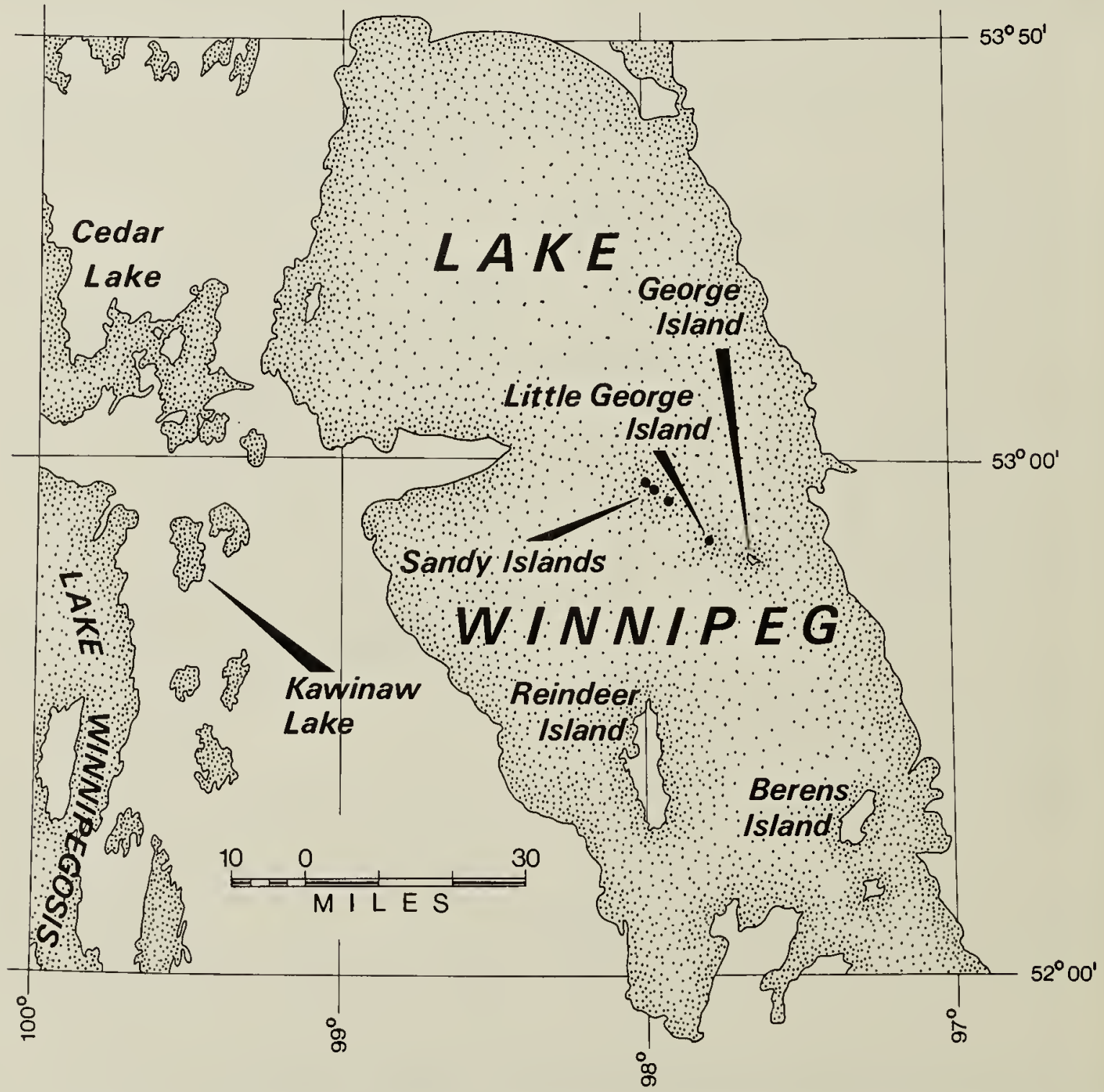

Fig. 1. Location of Little George Island in northern Lake Winnipeg and Kawinaw Lake. 


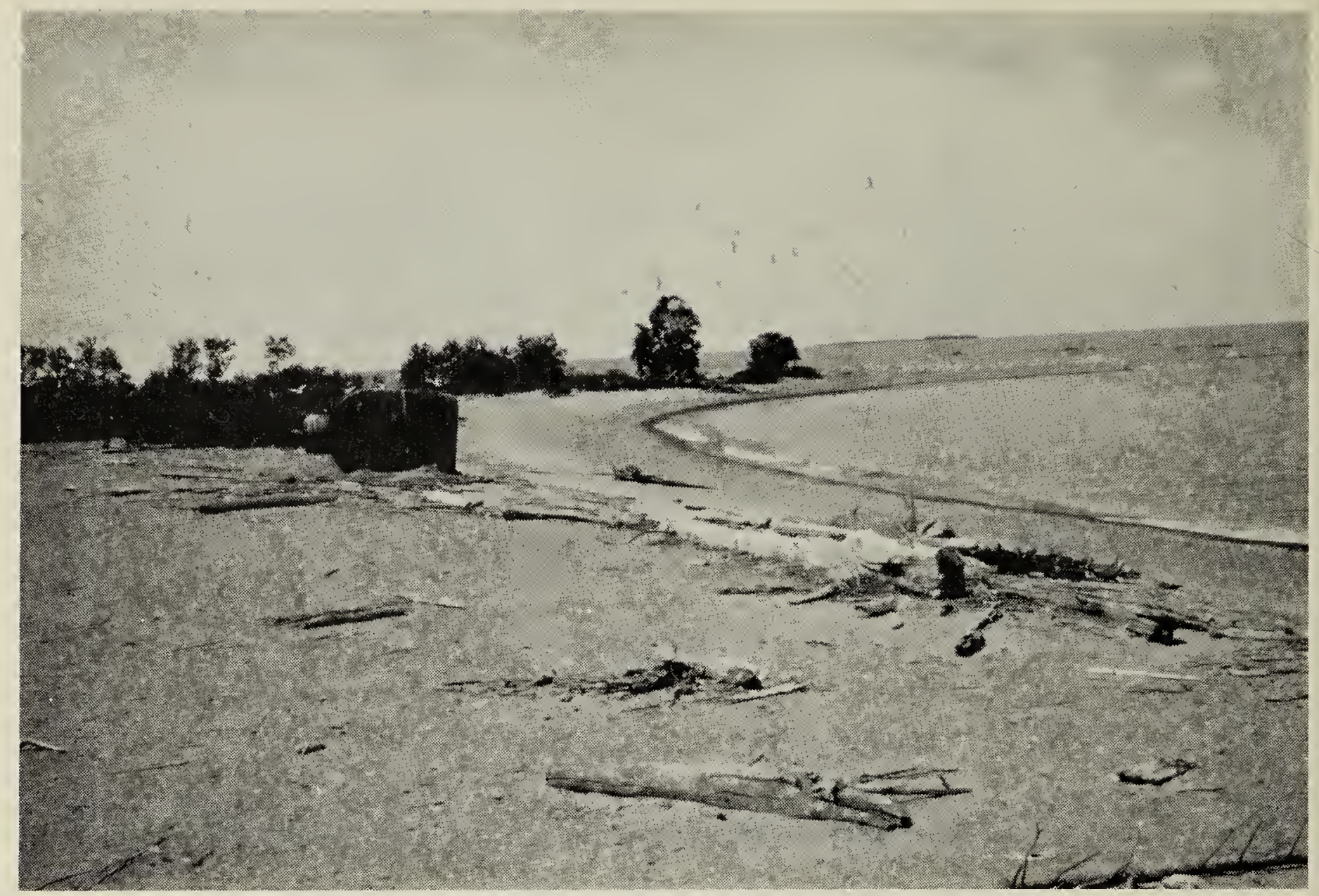

Fig. 3. Nesting habitat of Caspian Terns, Common Terns and Herring Gulls on Little George Island; massive object on beach is shipwrecked boiler. Two pairs of Herring Gulls nested in the boiler.

week of July 19-25, which is more pronounced for Caspians than Common Terns. This second peak probably represents mostly repeat laying, an average of 12 days after a gale occurred on July 8. One hundred and seven clutches were destroyed by that gale.

The clutch initiation of Common Terns at Kawinaw Lake in the beginning of the breeding season is shown in Table 1. From comparing Fig. 2 and Table 1 it can be seen that Common Terns at Kawinaw Lake started laying 10 days before those nesting on Little George Island. The 10 day delay in laying of Common Terns at Little George Island as compared to those at Kawinaw Lake does not appear to be related to differences in physiological changes brought about by a variation in day length as these two locations are at the same latitude. Ice disappeared from Kawinaw Lake and Lake Winnipeg in the first and last week of May respectively. The late disappearance of ice per se at Lake Winnipeg is not thought to be the cause for the late clutch initiation of terns there as the ice disappeared from that lake one and one-half weeks before the terns initiated laying. However, the long-lasting presence of ice may have retarded the appearance of small fish and the emergence of insects on which Common Terns at Little George Island were observed to feed (Vermeer, in press). A shortage of food at the start of egg-laying may inhibit clutch initiation. Murton et al. ("The food and growth of nestling woodpigeons in relation to the breeding season." Proc. Zool. Soc. Lond. 141:747-781, 1963) found that the main proximate factor inducing laying in Woodpigeons (Columba palumbus) was the availability of food.

\section{ACKNOWLEDGMENTS}

The assistance of Messrs. J. A. Windsor and D. R. M. Hatch with the collecting of data on Little George Island is much appreciated. 